\title{
Informação - um Produto Insubstituível na Estratégia de Marketing: Estudo de Caso Empresa E-Commerce
}

\section{Information - An Unreplaceable Product in the Marketing Strategy: E-Commerce Company Case Study}

\author{
José Leandro SEGURO
}

Universidade Federal do Paraná (UFPR), Ciências Sociais Aplicadas, Programa de Pós-Graduação em Gestão da Informação, Curitiba, PR, Brasil. ORCID: https://orcid.org/0000-0003-0625-3255. E-mail: leandrocontabeisufpr@hotmail.com

\section{Edelvino RAZZOLINI FILHO}

Universidade Federal do Paraná (UFPR), Ciências Sociais Aplicadas, Curitiba, PR, Brasil. ORCID: http://orcid.org/0000-0002-69209502. E-mail: razzolini@ufpr.br

\section{Everton de Barros FRANCO}

Universidade Federal do Paraná (UFPR), Ciências Sociais AplicadasCuritiba, PR, Brasil. ORCID: https://orcid.org/0000-0002-59200897. E-mail: evertaimme@gmail.com

Received 03/07/2021; Accepted 03/11/2021.

Editor: Marcele Elisa Fontana ISSN: 2594-8040

To cite this paper: Seguro, J.L., Razzolini Filho, E., \& Franco, E.B. (2022). Informação - um Produto Insubstituível na Estratégia de Marketing: Estudo de Caso Empresa E-Commerce. Journal of Perspectives in Management - JPM, 6, p. 1-13. https://doi.org/10.51359/2594-8040.2022.252295

Resumo: Este artigo objetiva analisar de que forma uma empresa de e-commerce, localizada em Curitiba-PR, coletam dados e como os transforma em informações úteis para construção da estratégia de marketing. O estudo tem cunho qualitativo, por meio de uma revisão bibliográfica de artigos sem corte temporal, estudo de caso único por meio de entrevista semiestruturada, com a finalidade de descrever um evento contemporâneo específico. Como resultado do estudo, foi constatado que a principal fonte de dados internos são os históricos de vendas. Por outro lado, como fontes externas, a empresa monitora informações de sítios de internet de empresas concorrentes. Após transformarem esses dados em informações, a empresa realiza seu planejamento e define sua estratégia de marketing, direcionando os anúncios e suas promoções, reduzindo os custos da operação e maximizando os resultados.

Palavras-chave: marketing da informação; produto informacional; informação como produto; decisão de marketing. 
Abstract: This article aims to analyze how an e-commerce company, located in Curitiba-PR, collects data and how it transforms them into useful information for building a marketing strategy. The study has a qualitative nature, through a bibliographic review of articles without time cut, the single case study through semi-structured interview, with the purpose of describing a specific contemporary event. As a result of the study, it was found that the main source of internal data is sales histories. On the other hand, as external sources, the company monitors information from the websites of competing companies. After transforming this data into information, the company carries out its planning and defines its marketing strategy, targeting advertisements and promotions, reducing operating costs, and maximizing results.

Key-words: information marketing; informational product; information as a product; marketing decision.

\section{Introdução}

Desde o pós-guerra, a demanda de serviços e produtos cresceu algo que possibilitou que as organizações se aperfeiçoassem. Juntamente com $o$ advento da informática unida às telecomunicações, mais uma vez esta evolução se fez importante por trazer avanços tecnológicos que criaram novos padrões de comportamento por consequência de consumo. Com esse aumento no consumo e acrescidos das novas tecnologias, nasceu o e-commerce (comércio digital). Segundo de Mendonça (2016), desde o surgimento do e-commerce, os clientes buscam melhores preços e melhores produtos, e mesmo em tempos de crise as pessoas não deixam de consumir.

Conforme Index (2021), no e-commerce as tendências de consumo já estavam em ascensão, mas devido à pandemia foram aceleradas. No entanto Guissoni, et al.,(2019), nos dizem que as empresas de e-commerce necessitam adaptar seus modelos de negócio. Estas devem estar atentas às mudanças no comportamento dos consumidores para que tenham chance de competir e de lucrar na era digital.

Para permanecerem competitivos e atrair novos clientes, as empresas de e-commerce usam ferramentas como: Google Ads e Google Analytics. Essas ferramentas geram insumos informacionais, que são utilizados na estratégia de marketing. Elencados nesta premissa têm-se o marketing da informação como uma abordagem alternativa ao marketing tradicional, uma vez que o enfoque não é somente na empresa, mas também no consumidor e sua percepção. Desta forma, o setor de marketing quando analisa a informação, deve lembrar-se das palavras de McCarthy (1978), o qual nos fala que por mais que um produto seja o melhor do mundo, será de pouca valia se não estiver onde o consumidor quiser e quando o quiser.

Junto desse pensamento, Lauterborn, et al.,(1994), assegura que, as empresas não podem mais vender toda a produção, e sim, apenas vender especificamente o que alguém quer adquirir, ou seja, a informação e o marketing também estão atrelados às ideias desses autores, e são um exemplo de como uma administração moderna deve pensar para atingir os resultados esperados. A partir desses pressupostos, tem-se o uso da informação como uma ferramenta imprescindível no auxílio empresarial. Segundo Laurentino (2016), a informação é considerada um ativo intangível, o qual para ser utilizada requer tratamento, portanto, a informação precisa ser trabalhada, a fim de explorar seu máximo potencial, sendo necessário que a informação seja clara, precisa, dirigida e rápida. Em concordância a, Silerová, et al., (2011), os dados e as informações tornaram-se um dos mais valiosos recursos organizacionais. Com base nisso, conota-se a importância de uma boa gestão informacional, na qual deve realizar-se um levantamento de mercado interno e externo para que se possa traçar a melhor estratégia para a empresa.

Nimmagadda, et al., (2018), dizem que gerenciar e entregar informações precisas em várias unidades operacionais são tarefas desafiadoras para tomar decisões nos negócios, e nesse 
ponto encontra-se o marketing da informação. Amaral (2011), explica o marketing da informação como o processo de gestão da informação, no tocante as etapas do ciclo da informação, como a coleta, tratamento, disseminação e o uso.

O marketing utiliza a informação como uma ferramenta importante, pois a mesma contribui ao processo de tomada de decisão, e dessa forma disponibiliza informações que sejam pertinentes às necessidades dos envolvidos nesse processo, sejam eles os empresários ou os consumidores.

Essa área de pesquisa de marketing auxilia o meio empresarial, bem como acadêmico, uma vez que o insumo informacional poderá assessorar aos empresários e aos estudantes a compreenderem a implicação social gerado por essas informações ou pela falta delas. Algo que ajuda no entendimento dos motivos de acontecer possíveis falhas durante o processo da criação do marketing.

Em síntese, Porter (1989), ressalta a importância da informação como insumo produzido e utilizado internamente pelas empresas para a tomada de decisão, pois a informação pode servir para a estratégia de marketing e assim lhe fornecer certa vantagem competitiva.

Considerando as constantes mudanças tecnológicas e novos sistemas de informações, fica evidente a importância de um estudo de caso que retrate este fenômeno contemporâneo do uso da informação para obter vantagens competitivas, tendo em vista que o mundo encontra-se na era da informação. Dentro desses pensamentos Garnov, et al., (2019), mostram como a análise de dados traz benefícios e também informações úteis para a tomada de decisão da gestão, e que gerentes usam a análise de dados para melhorar a eficiência e expandir o negócio.

A partir deste prévio embasamento, pontua-se o caráter necessário do marketing da informação na tomada de decisão. Uma vez que o valor inato do conhecimento tácito e explicito sempre trazem novas formas de entender o mercado e o consumidor. Por meio dessa comunicação, cria-se um vínculo mais eficaz entre as empresas de e-commerce e os consumidores, fazendo com que alavanque o consumo.

Sendo assim, esse artigo visa investigar como são gerados internamente os insumos informacionais e de que maneira contribuem para o planejamento e estratégia de marketing das organizações. Pautados nas premissas do marketing da informação, que apresentamos a inovação do uso da informação dentro dessa nova perspectiva mercadológica, algumas bases teóricas foram recolhidas e expostas nesse artigo como veremos nas seções seguintes.

\section{Referencial Teórico}

A pesquisa trouxe alguns pontos importantes para entendimento da utilização da informação como ferramenta de marketing, por isso apresentamos a seguir algumas referências teóricas que subsidiam a construção desse texto. Entre as quais se destacam: os conceitos de marketing; marketing da informação; informação e informação como produto; ou seja, uma divisão dos pontos teóricos que norteiam esse campo de estudo, sendo o cerne do estudo a informação como insumo na estratégia de marketing.

Segundo Razzolini Filho (2021), na atual era da informação, a informação é o ativo de suma importância para as organizações, necessitando fluir desde níveis operacionais até níveis estratégicos. A informação não é somente útil para as organizações, mas também, no meio acadêmico. Para Valentim (2010), a informação é útil tanto no âmbito acadêmico quanto no âmbito organizacional.

Tendo em vista que é necessário entender que os insumos informacionais devem ser algo que atenda necessidades, gere satisfação e proporcionem benefícios aos consumidores, ou seja, os gestores usuários da informação, que para Laurentino (2016), é um produto ativo e útil dentro do mercado na era da informação. Esse posicionamento atrela-se ao pensamento de Amaral (2013, 
p.4), “compreender e interpretar as necessidades do consumidor é um princípio fundamental na prática mercadológica". Visualizando a informação como insumo da sociedade tecnológica segue uma breve discussão sobre informação.

\subsection{Marketing}

O marketing pode ser entendido conforme Ângelo, et al., (2011), como uma filosofia de gestão administrativa na qual todos os esforços convergem em estabelecer, com a máxima eficiência possível, a satisfação das necessidades e desejos dos consumidores no sentido de extrair resultados positivos para a organização. Com a tentativa de alcançar a máxima eficiência, Satur et al., (2018), falam que o marketing sempre está em busca de informações, especialmente as emitidas pelos atores (consumidores, stakeholders, usuários) e assim continuará. O marketing segundo Silva, et al., (2019), tem como função principal desenvolver as organizações, pois acha maneiras de criar valor aos clientes, e pode ser a diferença entra obtenção do fracasso e o sucesso de uma organização.

No contexto do e-commerce se tem o marketing digital, o qual consiste nos 8 Ps, pontuados por Leal (2019), P1- Pesquisa - Usar informações para descobrir o perfil e hábitos do público-alvo;P2 - Planejamento - Fazer um planejamento de marketing ideal para o ambiente digital; P3 - Produção - Transformar ideias em aumento de vendas; P4 - Publicação - Escolher conteúdos publicitários persuasivos para serem publicados no site; P5 - Promoção - Fazer campanhas promocionais no ambiente digital a fim de gerar resultados no curto prazo; P6 Propagação - Instigar a rede a compartilhar o conteúdo do site de consumidor a consumidor; P7 Personificação - Construir uma comunicação personalizada por meio de segmentação do públicoalvo, com o objetivo de criar relacionamento; P8 - Precisão - Mensurar os resultados das ações, afim de perceber o que deu certo e o que deu errado para que possa alterar as estratégias quando necessário.

Estes pontos corroboram com Silva (2019), pois, o marketing digital é a utilização efetiva da internet como ferramenta, uma vez que envolve propaganda, publicidade, comunicação e todos os conceitos e recursos do marketing.

Além disso, evidencia-se que os produtos não são mais somente objetos tangíveis, até elementos como conceitos e ideais são mercadorias transpassando a ideia que os agentes de marketing tinham nos anos 60, criando assim, o desafio da gestão do marketing, o qual é segundo Satur et al. (2018), as organizações devem garantir que após o produto ser entregue supra as expectativas geradas pela promessa, com isso os clientes não compram apenas produtos ou serviços, mas o benefício gerado pelo produto.

Desta forma, como enquadrar a informação nessas metas do marketing atuais, transformando este antigo privilégio de poucos em algo acessível e desejável por consumidores modernos? Para sanar essa dúvida será apresentada a visão dos pesquisadores e estudiosos da área do marketing da informação.

\subsubsection{Marketing da informação}

Primeiramente, dá-se expor a definição de marketing da informação, bem como marketing dos produtos e serviços, pois, conforme Amaral (2011), todos possuem a informação como base. Como toda a ferramenta empresarial, Amaral (2008, p.34) diz que:

O marketing pressupõe a compreensão das necessidades, percepções, preferências e interesse pela satisfação e pelos padrões de comportamento da audiência-alvo, além da adequação das mensagens, da mídia, dos custos e das facilidades, a fim de maximizar suas atividades na área em que é aplicado. 
Para analisar tal objetivo, bem como a realidade que o profissional da área deve seguir, Amaral (2011, p.96), apresenta princípios do marketing e seus pressupostos da seguinte forma:

(a) comprometimento com a filosofia de marketing adotada pelos gestores da unidade de informação;

(b) suporte administrativo da alta direção da organização mantenedora da unidade de informação;

(c) desenvolvimento das atividades da unidade de informação com foco no cliente;

(d) preocupação com o atendimento ao público-alvo, receptividade às críticas, reclamações e sugestões;

(e) divulgação dos benefícios advindos da adoção das técnicas de marketing; e acima de tudo;

(f) destaque para o relacionamento entre a unidade de informação e seus públicos.

Atrelados a estes pressupostos, de acordo com Wildauer (2007, p.2), tem-se:

O processo gerencial de todo tipo de informação (tecnológica, científica, comunitária, utilitária, arquivística, organizacional, ou para negócios) em uma organização, um sistema, um produto ou um serviço sob a ótica de marketing, para alcançar a satisfação dos diversos públicos da organização, sistema, produto, ou serviço, quando são utilizadas técnicas na realização e valorização das trocas de valores, beneficiando todos os elementos, que interagem na troca, para garantir a sobrevivência da organização, sistema, produto ou serviço no seu mercado de negócio.

Estes são alguns pontos que necessitam entendimento para manusear as informações, tendo em vista que elas são um produto que deve ser gerida e utilizada. Desta forma, definir-se-á a informação para compreendê-la como um objeto plausível de abordagem no marketing atual.

\subsection{Informação}

Para uma breve compreensão acerca da informação, Fagundes et al. (2017), em seu estudo pontuam o caráter qualitativo da mesma: A qualidade da informação como produto e serviço. Como produto a informação deve atender as especificações de ser livre de erro, representação concisa, completude e representação consistente, também deve atender as expectativas do usuário como qualidade apropriada, compreensibilidade, interpretabilidade e objetividade.

A informação como serviço, deve ser oportuna, tempestiva, segura e utilizável, também deve conter credibilidade, ser acessível, facilidade de manipulação, reputação e deve conter valor agregado. Sendo assim, as organizações por meio da informação esperam encontrar soluções para os problemas e benefícios. Conforme Ângelo et al., (2011), destaca que as pessoas não compram produtos ou serviços, e sim, benefícios e soluções.

Estes pontos norteiam a função comercial da informação, liberada para ser algo analisável pela teoria do marketing. Assim, nota-se que a informação para Soares, et al., (2016, p. 875), "devidamente tratada gera conhecimento, passando a ostentar um aspecto econômico". Além disso, Amaral (2011, p.93), diz que, "a informação e o conhecimento são por natureza complexas, mutáveis e diversificadas". Tendo em vista, a dinâmica do mercado, devem-se ficar atento as mudanças e diversidades das fontes de informações.

No contexto do controle exercido com referência ao marketing, para Limański et al., (2018), a informação serve como uma ferramenta para melhorar o desempenho, fazendo comparações entre as referidas ações, seus resultados e atividades dos concorrentes. Por isso, atualmente os profissionais devem entender, segundo Amaral (2011, p.96), que "a informação é a matéria-prima para geração de conhecimento e ambos são ativos intangíveis de relevância estratégica na evolução da sociedade". 
Em razão disso, Soares et al., (2016, p.876), afirmam a importância da informação no atual mundo capitalista, e enfatizam a importância para o e-commerce, onde são coletados dados sobre os consumidores, posteriormente transformados em informações que servem de ponto de partida para direcionar as campanhas publicitárias, justificando assim, o sucesso dos e-commerce.

Para Satur et al., (2018, p.165) "o uso da informação no marketing é muito importante, pois alimenta o planejamento para ele tenha condições de retratar o que, de fato, precisa ser considerado naquela realidade." Posição que é complementada por Razzolini Filho (2021, p.100): "é essencial compreender que informação para negócio deve, sobretudo, subsidiar o processo de tomada de decisão, pois a informação é a matéria prima para o processo decisório". Esta posição reforça a de Curtin et al., (2018), onde a informação é insumo para tomar decisão.

Além disso, Laurentino (2016), aponta que a partir do momento em que os dados deixam de ser vistos como fatos registrados internamente, e começam a ser vistos como insumos informacionais, estes conseguem transformar-se em algo indispensável para as organizações. Esses dados são mantidos em arquivos ou documentos geridos internamente. Os documentos podem variar em espécie e mídia, mas sempre terão um valor e um preço dentro da sociedade da informação que o mundo tem construído desde os anos 50 do século XX.

\subsubsection{Valor econômico da informação}

Para adentrar ao estudo do marketing da informação, deve-se compreender a função econômica desse insumo. Para isso, Amaral (2011, p.88), menciona que, "seu valor econômico parte do pressuposto de que informação gera conhecimento e esse, quando acumulado, possibilita a produção científica e tecnológica e é responsável pela geração de bens e serviços". Para Freire (2015, p.155), isso faz com que a informação passe "a ter valor não só social, mas também econômico o que permite qualificar e quantificar as sociedades, conforme o seu acesso à informação e seu uso".

A vista disso, Soares et al., (2016, p.886-887), trouxeram:

A discussão sobre o valor econômico da informação e como utilizam nas operações empresariais, devido a atual revolução informacional está se vivendo novas relações jurídicas, também surgem novos direitos e garantias, sendo a informação de extrema valia, as estratégias de mercado ameaçam as normas jurídicas e as garantias constitucionais dos cidadãos.

Este artigo tira-lhe a visão de algo abstrato, no entanto é algo que tende a se depreciar com o tempo. Portanto, a informação é um ativo intangível que pode ser mensurada. Para isso, Moody et al., (1999, p.499-505), definiram sete leis para a mensuração desse ativo, e desta forma, apresentar como a ideia de algo intangível é válida no imaginário organizacional contemporâneo, além de servir como referência este trato à informação, dentro de sua utilização no campo de marketing.

Primeira lei: A informação é (infinitamente) compartilhável;

Segunda lei: O valor da informação aumenta com o seu uso;

Terceira lei: A informação é perecível;

Quarta Lei: O valor da informação aumenta com Precisão;

Quinta Lei: O valor da informação aumenta quando combinado com outras informações;

Sexta Lei: Mais não é necessariamente melhor;

Sétima lei: A informação não é esgotável.

As leis são baseadas na visão real de como atualmente as mentes tanto dos possíveis "consumidores", quanto dos "produtores" entendem a informação em suas várias faces sociais. Então, a informação é um produto? Essa possibilidade será desvendada na seção seguinte. 


\subsubsection{Informação como produto}

O que é a informação como produto? Segundo Razzolini Filho (2021, p.100), “os produtos e serviços informacionais podem ser comercializados, porém também podem entender os produtos e serviços de informação como sendo desenvolvidos para usuários internos ao negócio." Opinião apoiada também por Gonçalves et al., $(2008$, p.2), o qual enuncia que "a informação também pode ser compreendida como produto ou serviço que busca atender a um determinado fim", criando um mercado próprio no qual Amaral (2011, p.92), defende ser "composto por todas as pessoas e organizações que, além de terem concebível interesse pela informação, também devem ter os recursos certos e necessários para serem trocados por ela".

Deste modo, Amaral (2011, p.4), afirma que "os responsáveis pela oferta de informação devem conhecer as necessidades, os comportamentos e a satisfação dos indivíduos ou grupos de indivíduos que demandam, usam ou deveriam usar a informação oferecida". Por isso o marketing deve apresentar estratégias para que tais responsáveis pelo oferecimento de informações possam competir dentro do jogo de mercado como se fossem produtores ou varejistas de bens considerados mais tradicionais, porém com um aspecto moderno. A seguir, inclui-se o desenvolvimento metodológico das ferramentas de análise da informação dentro do marketing.

\section{Metodologia}

Foram realizadas buscas nas bases de dados: Scopus e Science Direct a partir dos descritores: marketing da informação; information marketing, informação como produto. $\mathrm{O}$ instrumento de pesquisa se deu por meio de uma entrevista semiestruturada, o método de pesquisa foi um estudo de caso em uma empresa de e-commerce de Curitiba, Paraná. Segundo Yin (2015, p.27), "um estudo de caso é uma investigação empírica que investiga um fenômeno contemporâneo dentro de seu contexto da vida real, especialmente quando os limites entre o fenômeno e o contexto não estão claramente definidos."

Além disso, o presente artigo optou, pela aplicação metodológica de pesquisa qualitativa, que conforme Cooper et al., (2016, p.164):

Inclui um conjunto de técnicas interpretativas que procuram descrever, decodificar, traduzir e, de outra forma, apreender o significado, e não a frequência, de certos fenômenos ocorrendo de forma mais ou menos natural no mundo social.

Tais opções fornecem a possibilidade de extrair informações da entrevista semiestruturada, conforme a transcrição da entrevista encontrada no apêndice A, fazendo com que se evidenciem os fatores relevantes que contribuem para elaboração de um exemplar marketing informacional e dessa forma, as empresas consigam atingir o maior número de consumidores.

Essas formas de agir na coleta de dados devem ser vistos à luz dos princípios da análise da informação no campo do marketing. Procedimento necessário para transformar os dados reais em um resultado palpável e útil para qualquer empresa que pretende manter uma eficiência produtiva na atualidade comercial na era da informação.

\section{Resultados e Análises}

Sobre o entrevistado: O executivo entrevistado tem 26 anos, sexo masculino, sendo o principal executivo da empresa, graduado em administração de empresas pela UFPR, possui MBA em inteligência de negócios também pela UFPR, e atualmente está cursando um segundo MBA em Digital Business pela USP.

Sobre a empresa: A empresa é um e-commerce, fundada em 2017. Trabalha com decoração no segmento de tapetes, o entrevistado não sabe ao certo quanto é a participação da empresa em nível nacional, no entanto ele acredita que entre 5 e $10 \%$, a empresa tem um centro de distribuição, mas atua principalmente com Crossdocking, onde consegue estoque do fornecedor e anunciam no 
seu site ou em Marketing Place. Somente a partir do momento que o cliente efetua a compra é que a empresa faz o pedido para o fornecedor, realizando o faturamento da compra e enviando para o cliente.

É feito um planejamento e estratégia de marketing principalmente no site, com o auxílio de duas agências, que visam atrair um público específico para o seu tráfego, pois os produtos têm preço acima da média para o segmento, custando de 1.000,00 a 2.000,00 reais um tapete, sendo seu público alvo mulheres de 35 a 45 anos, classe A, B e C. Atraindo esse público especifico a empresa tem uma maior conversão de vendas, que consiste nas pessoas que visitaram o site e efetuaram a compra.

São Paulo é o Estado que mais compra da empresa, no entanto não é a Capital, mas sim a região metropolitana e algumas cidades do interior depois disso vêm a Capital e logo após o Paraná.

O entrevistado descreve os dados como: "diamantes brutos, que precisam ser lapidados, para que possamos tomar as melhores decisões". A coleta de dados ocorre internamente por meio dos cadastros dos clientes e histórico de vendas, a empresa utiliza como ferramentas para gerenciar esses dados o Google Analytics. Depois de feita a devida análise, direciona para qual público especifico os anúncios na internet apareçam, na esperança de chegar a um potencial cliente. Uma informação importante para a empresa é a conversão de compra. Analisando o histórico de vendas, o perfil dos clientes, número de conversão, é que, a empresa toma as decisões estratégicas.

Após analisar os dados coletados, e transformados em informações é que a empresa consegue estabelecer uma relação para onde divulgar promoções, como frete grátis ou desconto à vista, otimizando a operação. Sabendo quais produtos devem ter mais em estoque e usar esse produto para fazer uma campanha, melhorando ainda mais o desempenho da empresa. Além das informações internas, a empresa utiliza informações externas para obter vantagens competitivas, essas informações são conseguidas em outros sites, buscando qual é a preferência dos clientes naquele momento.

\section{Considerações finais}

Para o presente estudo foi realizada uma análise qualitativa, baseada na entrevista fornecida pelo executivo da empresa em questão. Foi evidenciado o cuidado deste para com a coleta de dados informacionais, os quais são utilizados para descobrir mais sobre seus potenciais clientes e consequentemente aumentar suas receitas.

A estratégia adotada pela empresa configura um bom canal de vendas no ramo da decoração, associado ao um modelo eficaz de marketing onde a mesma tem o auxílio de duas empresas especializadas na captação de dados, faz com que seu e-commerce se sobressaia frente seus concorrentes, pois eles não inseriram apenas a ferramenta como uma plataforma de vendas, mas sim com um espaço primoroso, onde seu público alvo é prontamente atendido de forma cômoda e satisfatória.

Ao final da entrevista ficou visível que o e-commerce atrelado a uma boa estratégia de marketing é capaz de aumentar consideravelmente a receita da empresa, mesmo que o comércio virtual ainda seja visto como inseguro por algumas pessoas. Porém, a empresa em questão leva em consideração a opinião de seus clientes. Aumentando a conquistando de novos clientes se fidelizando-os a cada nova compra.

Neste sentido, o estudo empreendido demonstrou como a empresa coleta os dados e posteriormente os transforma em informações, reduzindo assim a operação da empresa e otimizando o desempenho. Como foi realizado um estudo de caso para descrever um evento contemporâneo específico, o estudo ficou limitado, pois, teve somente um entrevistado, podendo em estudos futuros ampliar esse número de entrevistados, ou realizar um estudo de múltiplos casos. 


\section{Referências}

Amaral, S. A. (2008). Marketing da informação: entre a promoção e a comunicação integrada de marketing.

Amaral, S. A. (2011). Marketing da informação: abordagem inovadora para a gestão de unidades de informação.

Amaral, S. A. (2013). Estudos de usuários e marketing da informação. Brazilian Journalof Information Science, 7(1), 3-25.

Araújo Freire de, G. H., Freire, I. M., de Araujo, V. M. R. H., \& da Costa, C. S. (2015). Marketing da informação em mídias virtuais: experiência com o facebook De olho na CI. Encontros Bibli: revista eletrônica de biblioteconomia e ciência da informação, 20(43), 153-172.

Cooper, D. R., \& Schindler, P. S. (2016). Métodos de Pesquisa em Administração-12a edição. McGraw Hill Brasil.

EY Future Consumer Index 2021. Disponível em: https://assets.ey.com/content/dam/ey-sites/eycom/pt_br/topics/consumer-products/ey-brasil-future-consumer-index-2021.pdf. Acesso em: 12 ago.

Fagundes, V. B., Bentancourt, S. M. P., \& Bastos, L. C. (2017, September). Qualidade da Informação na Revisão Sistemática de Literatura. In Anais do Congresso Internacional de Conhecimento e Inovação-ciki (Vol. 1, No. 1).

Janeiro, A. R. (2013). PORTER, M. Vantagem Competitiva: criando e sustentando um desempenho superior. OMNES HUMANITATE, 3(11), 66.

Garnov, A., Zvyagin, L., \& Sviridova, O. (2019). System data analysis: innovative technologies, methods and techniques.

GONÇALVES, Marcos R.; GOUVEIA, Sônia M.; PETINARI, Valdinéa S. (2008). A informação como produto de alto valor no mundo dos negócios. CRB-8 Digital, São Paulo, v. 1, n. 1, p. 43-54.

Guissoni, L. A., \& Farinha, R. L. (2019). E-commerce com resultado. GV EXECUTIVO, 18(1), 4042.

Laurentino, R. B. (2016). A importância do marketing e suas estratégias na promoção das unidades de informação e do profissional arquivista.

Leal, A., MElO, L., ROJAS, A. L. G., VIANA, L. M., CARVALHO, D., \& JÚNIOR, O. R. G. (2017). O uso da mídia no marketing estratégico. Revista Eletrônica de Divulgação Científica da Faculdade Don Domênico 10 Edição, Guarujá, 1-18.

Limański, A., Popławska, Ż., \& Drabik, I. (2018). Marketing information system andriskreduction in managing a company on foreign markets.

Mendonça, H. G. (2016). E-commerce. Revista Inovação, Projetos e Tecnologias, 4(2), 240-251.

McCARTHY, E. J. (1976). Marketing básico: uma visão gerencial.

Moody, D. L., \& Walsh, P. (1999, June). Measuring the Value Of Information-AnAsset Valuation Approach. In ECIS (pp. 496-512).

Nimmagadda, S. L., Reiners, T., \& Wood, L. C. (2018). On big data-guide dup stream business research and its knowledge management. Journal of Business Research, 89, 143-158. 
Razzoline Filho, Edelvino (2021). Gestão da Informação para negócios: como (melhor) administrar negócios. Curitiba: Juruá

Satur, R. V., Pinho Neto, J. A. S. D., \& Duarte, E. N. (2018). Redimensionamento do espaço e do tempo: a incerteza e os desafios da sociedade, da informação e do planejamento do marketing. Investigación bibliotecológica, 32(77), 151-173.

Schultz, D. E., Tannenbaum, S. I., \&Lauterborn, R. F. (1994). O novo paradigma do marketing: como obter resultados mensuráveis através, do uso do database e das comunicações integradas de Marketing. Makron Books.

Šilerová, E., Heynnyeová, K., \& Jarolímek, J. (2011). Architecture of a management information system for farmers. AGRIS on-line Papers in Economics and Informatics, 8(665-2016-45131), 163 169.

Silva, S. S., \&leão Mendes, G. (2019). Análise do marketing digital nas diretrizes empresariais. Caderno Profissional de Marketing-UNIMEP, 7(1), 75-90.

Soares, R. D. S. M., \& Barbosa, M. A. (2016). A Informação como Produto e a Proteção do Consumidor na Sociedade da Informação: Estudo de Caso. Revista Eletrônica do Curso de Direito da UFSM, 11(3), 870-889.

Valentim, M. L. P., Coneglian, A. L. O., Fadel, B., Santos, C. A. D., Almeida, C. C. D., Moraes, C. R. B. D., ... \& Guaraldo, T. D. S. B. (2010). Gestão, mediação e uso da informação. Cultura Acadêmica.

WILDAUER, Egon Walter. (2007). Marketing da Informação. (Texto de apoio - 9 pg.). Matinhos: UFPR-Litoral.

Yin, R. K. (2015). Estudo de Caso-: Planejamento e métodos. Bookman editora. 


\section{Apêndice A - Transcrição da entrevista}

Idade: 26 Sexo: $\mathrm{M}$

Tempo da gravação: 12 minutos e 2 segundos.

\section{Transcrição da entrevista}

Olá aqui é o Victor eu vou auxiliar o Zé respondendo esse questionário para sua pesquisa meu nome é Victor Hugo de Camargo e eu sou o proprietário da WP home um e-commcerce que atua principalmente no segmento de tapetes trabalhamos com decoração, mas o tapete sempre foi o carro-chefe da empresa.

\section{começando aqui pelo questionário meu nível de escolaridade?}

Eu Sou formado em administração pela UFPR e tenho um MBA inteligência de negócios, também, pela UFPR, hoje eu estou cursando, também, um outro MBA em digital Business pela USP.

É sobre a nossa organização a WP home nasceu em 2017 e como comentei a do segmento de e-commerce no ramo de decoração, mas principalmente no segmento de tapetes.

A gente não consegue ter uma ideia muito boa do percentual que ela atinge do Mercado Nacional, regional, principalmente por causa da pandemia decolou bastante eu diria que a gente pega uma fatia de de 5 a 10\% do mercado, talvez um pouquinho menos, mas somos uma empresa aí que já está algum tempinho no ramo e te espero que possamos continuar por muito mais

Hoje somos apenas e-commerce né, mas já temos planos para, para iniciar nossa loja hibrida e poder imigrar para o físico, também, é nós temos um centro de distribuição e atuamos principalmente com cross-docking que agora a gente consegue o estoque do fornecedor e o anuncia através do nosso site ou através de marketing places. É a partir do momento, que somente a partir do momento que o cliente efetuou a compra nosso site ou no Marketplace é que a gente efetua o pedido do produto ao fornecedor aí o fornecedor manda para gente, a gente fatura em nome do cliente e manda para ele, basicamente essa é a forma como atuamos no mercado hoje em dia,

\section{Próxima pergunta, a empresa realiza planejamento estratégia de marketing?}

Sim, tem todo um planejamento por trás e especialmente do nosso site, é, é muito difícil, você trabalha bem um site hoje em dia no mercado que a gente que a gente vê que é muito muito muito competitivo, é qualquer pessoa está ao alcance de qualquer informação com dois cliques no Google, com, enfim, é todo esse planejamento principalmente por trás do wphome.com.br a gente Faz com auxílio de duas agências para que possamos atrair melhor os clientes porque não basta só, também, han pagar o google Ads ficar esperando né.

$\mathrm{O}$ até na pergunta questiona estratégia de marketing a gente enfoca bastante em trazer um público um pouco mais qualificado, pra, pra o tráfico do nosso site, é principalmente porque os tapetes com os quais a gente trabalha eles têm um ticket um pouco mais elevado do que a média no setor, é a gente tá falando de tapete que pode custar 1000, 1500, 2000 muito mais e não adianta trazer qualquer um para o nosso site, a gente precisa trazer um alguém que esteja interessado já efetuar a troca do tapete investindo em decoração e que corresponde a esse tipo de público que pode arcar com um produto que um pouco mais qualificado, é toda a estratégia de marketing então ela vai um pouco mais para esse lado, han sempre tem promoções de, de datas festivas e tudo mais e todo o banco de dados que a gente usa em relação a este estilo de cliente é sempre voltado pro, pro público alvo que a gente considera a grosso modo a gente considera que a mulher de 3045 anos classes A, B, C e dessa e forma a gente consegue, é obter um resultado um pouquinho melhor ali na conversão de vendas no WPhome.com, em relação Marketplace a gente não se aplica muito porque o próprio Marketplace já faz esse trabalho então vou focar um pouco melhor no nosso site. 


\section{Como são coletados os dados internamente?}

A gente tem sempre o cadastro dos clientes nossos sites, tem sempre o cadastro do cliente em nosso site e a partir disso a gente já consegue definir alguns pontos, além disso, é sempre mais fácil utilizar o Google Analytics, com a questão de google ads, pra, pra onde direcionar as campanhas né para que eles não cheguem uma pessoa que não tem absolutamente nenhuma nada a ver né como que a gente está buscando, então, dessa forma, que é melhor coletado o dado.

Como esses dados são tratados e transformados em informações? Interessante, é primeiramente a gente faz a correlação né do que a gente acredita que seja ao público-alvo que é com base já no histórico de vendas e tudo mais e cruza com o tipo de público que a gente quer atrair, sempre pensando alargando um pouco mais a ser mulher de 3045 anos a gente responde um pouco mais as campanhas de internet, e a partir disso a gente consegue direcionar para onde quer que o anúncio apareça, pra quem quer que os anúncios apareçam, é depois e se isso pode, pode virar um potência cliente, né alguém que vai entrar no nosso site pode efetuar compra, a depois disso a gente avalia principalmente a conversão né que o número de clientes que entram na nossa página e de fato compram algo, é nem sempre isso ocorre, então a conversão, ela é o número um pouco mais baixo, mas a gente está sempre atento e como que tá, é a questão essa, essa questão principalmente né é muito, vejo que muitas empresas elas trabalham simplesmente trazer pessoas pro, pro site é a mesma coisa que trazer literalmente qualquer uma por uma loja física né, mas com a internet a gente consegue delegar melhor isso então a gente se atenta muito melhora a questão de conversão e esse é o principal indicador né, é reforçando a conversão de pessoas que entram no site e compram, essa relação, se ela chegar a 1\% já é, já é muita coisa, entrou mil pessoas um por cento comprou, nossa tá bom, na internet está ótimo na verdade. E é assim que a gente consegue transformar isso em informação, em decisão, em decisão estratégica, transformar isso, criticar esse tipo de número, para poder tomar uma ótima decisão.

\section{Pergunta seguinte, como a organização utiliza as informações para estratégia e planejamento de marketing?}

Bom, dessa forma, acredito que tenha comentado bastante já em relação a isso, mas são principalmente os históricos de vendas que a gente consegue trabalhar uma base de dados muito grandes, pegar o principal público-alvo né, a partir disso a gente consegue pegar o ticket consegue pegar qual tipo de produto para aquela determinada época do ano tem saído mais, para qual região e isso impacta bastante e a partir disso a gente consegue alimentar a, a nossa base, para tomar uma boa decisão. Quanto a estratégia de marketing né porque a gente sabe que São Paulo é o estado que mais compra da gente, acredito que seja muita gente. A gente reparou que não é São Paulo capital $\mathrm{m}$ si, é região metropolitana é alguma cidades do interior em específico, depois disso, vem sim, a São Paulo capital e aí é que o Paraná. E a partir disso, a gente consegue estabelecer uma relação para onde divulgar mais por exemplo: uma promoção de frete grátis. Poh vale a pena colocar um frete grátis para São Paulo e região metropolitana e São Paulo interior, porque não tem um curso de frete muito alto e é algo que chama muito atenção do nosso, nosso cliente final né. Então é dessa maneira, que a gente consegue utilizar e as informações crítica os números de tomar uma ótima decisão.

\section{Última pergunta, como as informações geradas internamente, como as informações geradas internamente pode-se alcançar vantagem competitiva?}

Com certeza, a vantagem competitiva é a expressão, diária aqui no pelo menos na WP, é as informações a gente consegue pegar elas de qualquer lugar, é literalmente de qualquer lugar, se a gente entrar no site da Americanas por exemplo digitar tapete, os tapetes que apareceram por primeiros são os tapetes mais procurados por lá, então já consegue ver o que que o público está mais afim. Quais são os mais populares e tudo mais. É e se você olhar para dentro da organização poxa tivemos mais de 1020 mil vendas aqui, 25000 mil vendas, desde que a gente começou, são muitos dados, onde consegue filtrar pra quais regiões principalmente tem saído mais. Como 
comentei anteriormente, pra definir um frete grátis, conseguimos determinar qual o público principal que queremos atingir, conseguimos determinar qual o tipo de produto a gente precisa ter mais em estoque, que na hora de fazer uma campanha, fazer essa campanha em cima desse produto e atender a todos os clientes que vierem atrás né e tudo isso otimiza a operação da empresa tudo isso permite que a gente tenha um ótimo desempenho se o concorrente tá fazendo não tá não sei, mas a empresa tem ido bem ultimamente, muito bem obrigado. E isso é vantagem competitiva, e isso tudo eu comento sempre em cima do nosso, do nosso site que é através do qual a gente faz as campanhas de marketing, e traça esse planejamento, essa estratégia, se você pensar além no Marketplace por exemplo, que tem uma competição absurda porque são vários e vários Lojistas anunciando as vezes o mesmo produto, acaba sendo a mesma, mesma ideia, porque com essas estratégias de marketing que a gente já define pro site, a gente consegue pensar melhor para dentro do marketing place, porque a gente sabe quando aderir uma promoção de frete grátis lá dentro, quando oferecer um desconto à vista para o cliente, e por aí vai, então acredito que essa seja a expressão mais importante para quem quer se destacar seja no varejo ou seja na internet, no varejo digital daí no caso, porque como eu comecei lá no início qualquer pessoa está dois cliques de distância de qualquer informação, e esses dados que a gente gera principalmente aqui dentro da empresa são diamantes brutos que a gente precisar lapidar, poder, extrair ótimas, ótimas decisões a partir dele. Espero que tenha ajudado desejo uma boa tarde para todos. 